\title{
The future is in childhood: Evaluation of the quality of sustainability programmes in the early years
}

López-Alcarria, Abigail $^{\text {la }}$, Gutiérrez-Pérez, José ${ }^{1}$, Rodríguez-Sabiote, Clemente ${ }^{1}$ and PozaVilches, Fátima ${ }^{1}$

${ }^{1}$ Department of Methods \& Research in Diagnosis \& Education, Granada 18071, Spain

\begin{abstract}
During the last decade Environmental Education (EE) programs have drawn attraction from both experts and educators as a way to answer the increasing preoccupation about the different challenges and problems faced by the Environment. For this reason, many schools have started programmes and strategies related to EE with different success. In this work, we have carried out a case study over 30 teachers of Early Years Education (EYE), working at preschools in Granada, Spain, in order to assess the implementation of Environmental Education in their daily practice. By means of an interview protocol we have gathered information about 15 different categories encompassed in topics which are central to EE such as curricular innovation, participation of the educational community and sustainable management of the school. Results show how teachers are positive regarding the inclusion of $\mathrm{EE}$ in their daily practice and the participation of the community. On the other hand we observed the difficulties faced by the educators to effectively implement EE programs due to lack of economic support by the Administration and the need to carry out an objective consultancy to overcome possible biases which may exist when teachers evaluate their own performance.
\end{abstract}

Keywords: Environmental education; early years education; case study; survey; value scale.

\section{Introduction}

What kind of planet will we leave to our descendants? Climate change, desertification, thawing of the Poles, deterioration of the ozone layer; these are some of the examples of the progressive worsening of the environmental reality we are facing; problems, in which the anthropocentric attitude of human beings, has great responsibility.

Educational programs have the obligation of incorporating convincing answers to these challenges, so they contribute to the transition towards a new model of society based on the

\footnotetext{
${ }^{a}$ Corresponding author: abigail@ugr.es
} 
development of environmental ethics which promote protection of the environment in a sustainable and durable way.

\subsection{The importance of environmental education}

Many of the students starting their schooling will hold in the future management positions in companies with environmental responsibilities, political charges in which they will make high level decisions, or they will simply be citizens committed with new forms of mobility, consumption, use of water and natural resources.

Environmental Education (EE) is a powerful tool to help us in educating future generations, as it can be seen as a permanent process in which individuals and communities become aware of their environment and acquire the knowledge, values, skills, experience and determination which prepare them to act, individually or collectively, in the resolution of current and future environmental problems.

\subsection{The importance of environmental education}

There is a growing interest in the study of EE in Early Years Education (EE) among researchers from different countries including Australia, [18, 9], the USA [10, 11, and 4], the UK [2, 20], Mexico [3], and New Zealand [8].

A good example that examines this field of research can be found in [15], which includes a thorough review of the aforementioned papers and many others related to EE and Education for Sustainable Development (ESD) that were published from 1996 to 2003. One of the goals of the authors is to determine how EE and ESD are approached by researchers in EYE. In this regard, they identified two major approaches in the literature: (1) How teachers understand EE/EDS and (2) How they apply it in their daily practice. The understanding of EE/EDS entails teaching facts about the environment, manipulating the behavior of children and developing their critical thinking skills. Regarding the application of EE/EDS in the curricula, two different trends were found, the first one analyzing the potential of the implementation of EE/EDS in EYE and the second one assessing the efficiency with which it is actually implemented.

The results of the studies vary considerably between countries, states, provinces and even cities since the economical, geographical, social and educational contexts differ. In spite of this fact, an important part of the findings are applicable and of interest worldwide, therefore our interest to follow the steps initiated by researchers around the world to study the current situation in the city of Granada in Southern Spain.

The work of our research group deals with all the topics aforementioned at all education levels. We have carried out studies oriented to analyze how teachers understand EE/ESD, their degree of interest in the topic, how they apply it in their daily practice and the potential of its application in schools having never applied it. Additionally, we have also developed different consultancies in which the strengths and weaknesses of different programs were evaluated $[5,6,7,13,14,16,17,21$, and 22].

The work presented in this paper is oriented to apply our experience to study and evaluate EE and ESD programs in EYE. More specifically, as a first step in our immersion, we will focus on analyzing teacher's insight of EE, their opinion about its importance and the techniques and strategies they follow to include it in their daily practice. The remainder of the paper is structured as follows; section 2 defines the motivation and the objectives of the study; section 3 explains the methodology in detail; section 4 presents and analyzes the qualitative and quantitative results and finally, future work and the conclusions are drawn in section 5 . 


\section{Motivation and Objectives}

\subsection{Motivation}

To our knowledge there are no previous studies of the application of EE in preschools in the city of Granada. Therefore, our main motivation was to fill this gap since we believe it is of crucial importance that EE also takes place in the initial phase of formal education in order to address pro-environmental values with future generations and promote commitment with sustainable development models.

\subsection{Aim and research questions}

The main objective of this research is to study how preschool teachers implement EE in their daily practice and the degree of sustainability of the policies and infrastructures of the education centers they work in. More specifically we seek answers for the following questions:

- How is EE integrated in the daily practice through curricular innovation?

- To what degree is the community involved with the EE practices of the school?

- Are the school and its resources managed in a sustainable way?

\section{Methodology}

\subsection{Sample}

We have interviewed 30 teachers from 10 different preschools in Granada (Spain) who were selected using a non-probabilistic sampling of intentional character, since we consider they fairly represent the population under study. $86.7 \%$ of interviewees were women, while $13.3 \%$ were men.

\subsection{Data collection tools}

The employed technique to gather information is based on an interview protocol composed of 50 questions. The interview includes questions which are related to three main aspects: curricular innovation, participation of the educational community and sustainable management of the school. These three main aspects are, in turn, subdivided into 15 different categories, namely: (1) Social climate, (2) Collaborative work environment, (3) Cross-curricular EE, (4) EE in practice, (5) Diffusion of EE, (6) Inclusion of the community in the school practices, (7) Level of participation of the community, (8) Relationship between the school and its environment, (9) Water management, (10) Waste management, (11) Energy management, (12) Mobility, (13) Green areas, (14) Resources and (15) their responsible consumption.

Additionally, in order to quantitatively analyze the information, we developed a scale of value in which subjects evaluated from 1 (non-satisfactory) to 5 (highly satisfactory) their overall satisfaction with the 15 categories of study. The methodological approach is, therefore, twofold as it comprises both qualitative and quantitative analysis. Quantitative analysis is employed to ease the identification of the overall strengths and weaknesses of the application of EE in the curricula, while qualitative analysis allows us to deepen the evaluation. 


\subsection{Data analysis tools}

Regarding the quantitative analysis, we have elaborated a classification of the addressed topics from an analytical triangulation strategy [23] in which we have considered both descriptive (means and percentiles) and multivariate (hierarchical cluster analysis) levels. The mean of answers to the scale value are depicted in table 1.

Following the analytical triangulation strategy explained in we have, in first place, implemented the classification of the arithmetic mean of the 15 categories using the 50th percentile ( $\mathrm{P} 50=4$ in this case) as the threshold to divide the answers in two groups. Thus, those categories showing means lower than 4 were classified as moderately satisfactory while those higher than 4 were labeled as highly satisfactory. Figure 1 (left) shows a histogram and the value of satisfaction assigned to each category.

After the descriptive classification, we implemented a multivariate content classification using hierarchical cluster analysis through Ward's method and the squared Euclidean distance. The result of this analysis is shown as a dendogram in figure 1 (right).Regarding the analysis of qualitative data, the transcription of the interviews was codified using Nudist Vivo, allowing us to match the testimonies to the different categories.
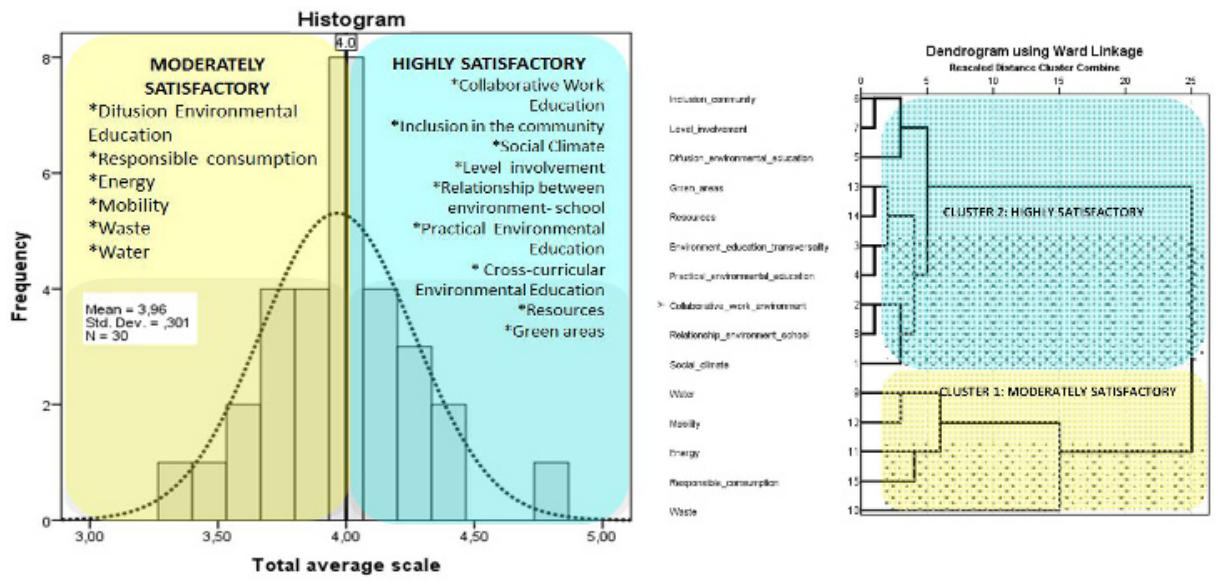

Fig. 1. Histogram of data obtained from the value scale (left). Dendogram of the scaled value obtained using Ward Linkage (right).

Table 1. Mean and standard deviation of the answers to each category of the scale value.

\begin{tabular}{|c|c|c|c|}
\hline Category & Mean & Category & Mean \\
\hline Collaborative work environment & $4.60 \pm 0.56$ & Green areas & $4.10 \pm 0.60$ \\
\hline Inclusion of community & $4.50 \pm 0.68$ & Difusion of EE & $3.93 \pm 0.82$ \\
\hline Social climate & $4.47 \pm 0.62$ & Responsible consumption & $3.87 \pm 0.86$ \\
\hline Level of involvement of community & $4.33 \pm 0.71$ & Energy & $3.67 \pm 0.84$ \\
\hline Relationship school-environment & $4.30 \pm 0.65$ & Mobility & $3.17 \pm 0.69$ \\
\hline Practical EE & $4.27 \pm 0.69$ & Waste & $3.00 \pm 1.25$ \\
\hline Cross-curricular EE & $4.20 \pm 0.71$ & Water & $2.93 \pm 0.98$ \\
\hline Resources & $4.13 \quad 0.34$ & & \\
\hline
\end{tabular}




\section{Discussion of results}

\subsection{Qualitative analysis}

When analyzing the testimonies related to curricular innovation we observe how teachers are involved with EE "The social climate is very rich and participative. That's the general tone in this school", "We encourage collaborative and experimental work at many levels", "EE is part of the educational project of the school", "All teachers are aware of the importance of addressing EE topics in the ages we work with" and carry out different activities "we have a vegetable garden in which we grow lettuce and tomatoes. We have different natural elements we work with in the classroom such as insects, stones and shells".

When asked about citizen participation, most subjects claimed they were very happy with the relationship of the school with the families of the students as well as with the surrounding environment "families are highly interested with all the educational elements, we have different means to interchange information in a continuous way", "parents have participated in different research projects, helping their children to prepare conference talks" "we are in touch with a group of farmers who have ecological vegetable gardens next to the river. We have visited them and they have also visited the school. There is also a close relationship with the neighborhood association. We are also working with the city hall in a project called "my neighborhood is my home".

Regarding the sustainable management of the school and mobility the testimonies are less positive "there is a drinking fountain in the courtyard with a continuous water flow. We have requested the city hall to install a push button", "the tanks of the toilet are only filled to half of their capacity. We encourage responsible consumption in the assembly", "there are no solar panels, we are considering to install them next year", "we have got the city hall to install dumpsters in the neighborhood by means of an awareness campaign", "most parents bring their children by car", "mobility causes a large problem, cars invade the sidewalks surrounding the school", "the menu of the canteen is controlled by dieticians. The cooks assist to yearly seminars in which they analyze the types of food, the Mediterranean diet. There is continuous innovation", "In order to control the surplus of food we try to adjust the amount that is cooked. To do so, the attendance sheet is given to the cooks everyday".

\subsection{Quantitative analysis}

From the obtained results, it can be highlighted that in all 15 categories, the average score is above 2.93. For this reason, we can affirm in global terms that the perception of the subjects regarding the implementation of EE in their schools is moderately high. Secondly, we must emphasize that both analysis strategies have established two groups of contents: those that teachers believe have been addressed in a moderately satisfactory way and those which were applied in a highly satisfactory way. Among the first set of aspects, it is important to notice that they were all related to the sustainable management of the school (water, waste, mobility, energy and responsible consumption), which is to a large extent not controlled by the teachers.

\section{Conclusions and future work}

We have carried out a first approximation to the situation of EE in EYE in the city of Granada (Spain). By interviewing 30 teachers from 10 different schools we have studied 
how they apply EE in their daily practice, what kind of activities they make, what values they promote, as well as the involvement of the community in the dynamic of the schools and the sustainable management of the resources.

We have confirmed there is great disposition by the teachers to start addressing EE topics at early ages. We have also observed that the valuation was more positive towards those aspects related to curricular innovation and citizen participation. This is mainly due to the fact that teachers feel they can directly influent the social climate, work as a team, include $\mathrm{EE}$ in a cross-curricular way, encourage the participation of families and other external agents, visit the environment and use the green areas they have access to. On the other hand, we have observed there are other aspects central to EE and, in which teachers have little range of action, such us the sustainable management of the school and mobility which need further work and support from the administration. The lack of funds hinders the adaptation of infrastructures, and the way they are managed, to warrant coherence with the values transferred to children in the classrooms.

Future work will be oriented to implement a consultancy process using EE principles and standards to objectively determine the quality of the implementation of $\mathrm{EE}$ in $\mathrm{EYE}$, and to identify possible subjective biases in the responses of the subjects. Additionally, the consultancy will include a series of strategies and recommendations to be followed by both the Administration and teachers to improve the implementation of EE.

\section{References}

1. Altman, D.G., Practical statistics for medical research. New York: Chapman and Hall, (1991).

2. Barratt, E.; Barratt, R. \& Scott, W., Engaging children: research issues around participation and environmental learning, Environmental Education Research, 13:4, 529-544, (2007).

3. Barraza, L. \& Walford R. A., Environmental Education: A comparison between English and Mexican school children, Environmental Education Research, 8:2, 171186, (2002).

4. Basile, C.G., Environmental Education as a Catalyst for Transfer of Learning in Young Children, The Journal of Environmental Education, 32:1, 21-27, (2000).

5. Burgos, O., Evaluación de la calidad de los establecimientos certificados ambientalmente en BioBio (Chile) en comparación con Granada (España). PhD. Thesis, Universidad de Granada, Spain, (2011).

6. Burgos, O., Perales, F., \& Gutiérrez, J., Evaluación de la calidad de los establecimientos educativos incorporados al sistema nacional de certificación ambiental de la provincia de BioBio (chile). Profesorado: Revista de curriculum y formación del profesorado 14:2, (2010).

7. Burgos, O., Gutiérrez, J. \& Perales, F.J., Evaluación de la calidad de ecoescuelas. Un estudiocomparado entre Chile y España. Interciencia 37:5, 340-349.

8. Duhn, I. (2012). Making 'place' for ecological sustainability in early childhood education, Environmental Education Research, 18:1, 19-29, (2012).

9. Dyment, J. E.; Davis, J.M.; Nailon, D.; Emery, S.; Getenet, S.; McCrea, N. \& Hill, A. The impact of professional development on early childhood educators' confidence, understanding and knowledge of education for sustainability,Environmental Education Research, 20:5, 660-679, (2014).

10. Ernst, J., Early childhood educators' use of natural outdoor settings as learning environments: an exploratory study of beliefs, practices, and barriers, Environmental Education Research, 20:6, 735-752, (2014). 
11. Ernst, J. \& Tornabene, L., Preservice early childhood educators' perceptions of outdoor settings as learning environments, Environmental Education Research, 18:5, 643-664, (2012).

12. Fleiss, J.L., Statistical methods for rates and proportions, 2nd edition. New York: Wiley, (2000).

13. Gutiérrez, J. \& Perales, F.J., Ambientalización curricular y sostenibilidad. Nuevos retos de profesionalización docente. Profesorado: Revista de Curriculum y Formación del Profesorado, 16:2, 5-14, (2012).

14. Gutiérrez, J. \& Galván, L., Educational Guidance on water under the paradigm of complexity as a result of a comparative study between Spain and Mexico. Manuscritp submitted for publication, (2015).

15. Hedefalk, M.; Almqvist, J. \& Östman, L, Education for sustainable development in early childhood education: a review of the research literature, Environmental Education Research. (Pre-online access), (2014).

16. López, A.; Gutiérrez, J; Perales, F.J. \& Burgos, O., Greening the curricula: A comparison between Primary and Secondary Eco-school Projects. The International Journal of Sustainability Education, Volume 9, Issue 2, pp.1-18, (2013).

17. López, A.; Gutiérrez, J.\& Poza, F., Preschool Education Professionals as Mediators of Environmental Health Education. Procedia Social and Behavioral Science, Volume 132, 15, pp. 639-646, (2014).

18. McNichol, H.; Davis, J.M. \& O’Brien, K.R., Anecological footprint for an early learning centre: identifying opportunities for early childhoodsustainability education through interdisciplinary research, Environmental Education Research, 17:5, 689-704, (2011).

19. Moseley, C.; Desjean-Perrotta, B. \& Utley, J., The Draw-An-Environment Test Rubric (DAET-R): exploring pre-service teachers' mental models of the environment, Environmental Education Research, 16:2, 189-208, (2010).

20. Peacock, A., Young children and the environment: early education for sustainability, Environmental Education Research, 17:2, 284-286, (2011).

21. Poza, F.; Gutiérrez, J. \& López, A., Greening Spanish primary schools: students and teachers attitudes to centres committed to sustainability. Manuscript submitted for publication, (2015).

22. Poza, F.; Gutiérrez, J.\& López, A., The Sustainable View of Childhood: A Case Study in a Metropolitan Municipality. Procedia Social and Behavioral Science, Volume 132, 15, pp. 570-576, (2014).

23. Rodríguez, C.; Pozo, T. \& Guitiérrez, J., Analytical triangulation, a resource for the validity of recurrent survey studies and reply researches in Higher Education. Relieve, $12: 2,(2006)$.

24. Stanišiæ, J. \&Maksiæ, S., Environmental Education in Serbian Primary Schools: Challenges and Changes in Curriculum, Pedagogy, and Teacher Training, The Journal of Environmental Education, 45:2, 118-131, (2014). 